Article

\title{
Correlations Between Trace Elements in Selected Locations of the Human Brain in Individuals with Alcohol Use Disorder
}

\author{
Cezary Grochowski ${ }^{1,2, *(1)}$, Magdalena Szukała ${ }^{1}$, Jakub Litak ${ }^{2}$, Agnieszka Budny ${ }^{1}$,

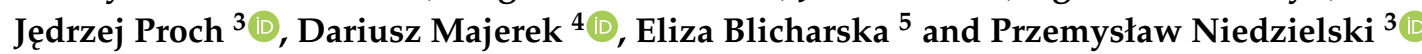 \\ 1 Department of Anatomy, Medical University of Lublin, Jaczewskiego 4, 20-090 Lublin, Poland; \\ medszukala@op.pl (M.S.); aguskabudny@gmail.com (A.B.) \\ 2 Department of Neurosurgery and Pediatric Neurosurgery, Medical University of Lublin, Jaczewskiego 8, \\ 20-954 Lublin, Poland; jakub.litak@gmail.com \\ 3 Faculty of Chemistry, Department of Analytical Chemistry, Adam Mickiewicz University in Poznań, \\ 89B Umultowska Street, 61-614 Poznan, Poland; jed.proch@gmail.com (J.P.); pnied@amu.edu.pl (P.N.) \\ 4 Department of Applied Mathematics, University of Technology, Nadbystrzycka 38D, 20-618 Lublin, Poland; \\ d.majerek@pollub.pl \\ 5 Department of Analytical Chemistry, Medical University of Lublin, Chodźki 4a, 20-093 Lublin, Poland; \\ bayrena@o2.pl \\ * Correspondence: cezary.grochowski@o2.pl
}

Academic Editor: Ki-Jung Paeng

Received: 11 November 2019; Accepted: 10 January 2020; Published: 15 January 2020

\begin{abstract}
Trace element distribution varies in different locations of the human brain. Several elements were found to cause various negative effects, such as neurodegeneration. In this paper, we analyzed the interactions between seven trace elements: zinc ( $\mathrm{Zn})$, selenium (Se), manganese $(\mathrm{Mg})$, iron (Fe), copper $(\mathrm{Cu})$, chromium $(\mathrm{Cr})$ and cobalt $(\mathrm{Co})$ in individuals with alcohol use disorder (AUD) and individuals without (control group). Brain tissue samples from 31 individuals with AUD and 31 control subjects were harvested. Inductively coupled plasma optical emission spectrometry was used for trace element determination. In the control group, there were several positive correlations between $\mathrm{Cr}, \mathrm{Cu}, \mathrm{Fe}$ and $\mathrm{Mn}$. In the AUD group, positive correlations between $\mathrm{Co}$ and $\mathrm{Cr}, \mathrm{Cu}, \mathrm{Fe}, \mathrm{Mn}, \mathrm{Zn}$ were found. The majority of correlations between $\mathrm{Zn}$ and other elements are positive. In the studied group, $\mathrm{Mn}$ had strong positive correlations with $\mathrm{Co}, \mathrm{Cr}, \mathrm{Cu}$ and $\mathrm{Fe}$. The strongest positive correlation found between average element concentration was between $\mathrm{Cu}$ and $\mathrm{Cr}$. The knowledge of kinetics and metabolism of trace elements as well as the impact of alcohol on these processes is essential for understanding the pathological processes and functioning of human brain tissue.
\end{abstract}

Keywords: trace elements; correlation; brain; alcohol; alcohol use disorder

\section{Introduction}

Trace element distribution varies in different types of human tissue [1-3], as well as in different locations of the human brain. Several elements were found to have negative properties [4], inducing oxidative stress processes, and thus neurodegeneration [5-7]. The homeostasis of biometals is well regulated in healthy human brains and improper function of these systems may cause dysfunction of physiological brain processes [8]. The connection between improper trace element distribution and neurodegenerative diseases such as Alzheimer's is well described in the literature [6]. Chronic copper, zinc and iron exposure was found to alter the processes of disease-associated proteins such as amyloid beta, amyloid precursor protein and tau protein. 
Alcohol consumption is an important risk factor for disability, illness [9,10] and increased mortality [11]. People who regularly drink large amounts of alcohol, which can be defined as more than $40 \mathrm{~g}$ of pure alcohol per day by men and $20 \mathrm{~g}$ of pure alcohol per day by women are particularly vulnerable [12]. Not only is alcohol a source of trace elements itself, but chronic consumption of ethanol is a cause of malabsorption, malnutrition and is associated with vitamin and trace element deficiencies [13]. The correlations between trace elements in the human brain are still poorly described. In this paper, we analyzed the interactions between seven trace elements: zinc (Zn), selenium (Se), manganese $(\mathrm{Mg})$, iron $(\mathrm{Fe})$, copper $(\mathrm{Cu})$, chromium $(\mathrm{Cr})$ and cobalt $(\mathrm{Co})$ in individuals with alcohol use disorder (AUD) and individuals without (control group).

\section{Results}

We discussed correlations that showed a strong or moderate association $(R \geq 0.7)$ presented in Figure 1 and Table 1 in more detail. Among the studied relationships, many correlations were found in different areas of the brain-the results are presented in Figures 2-11.
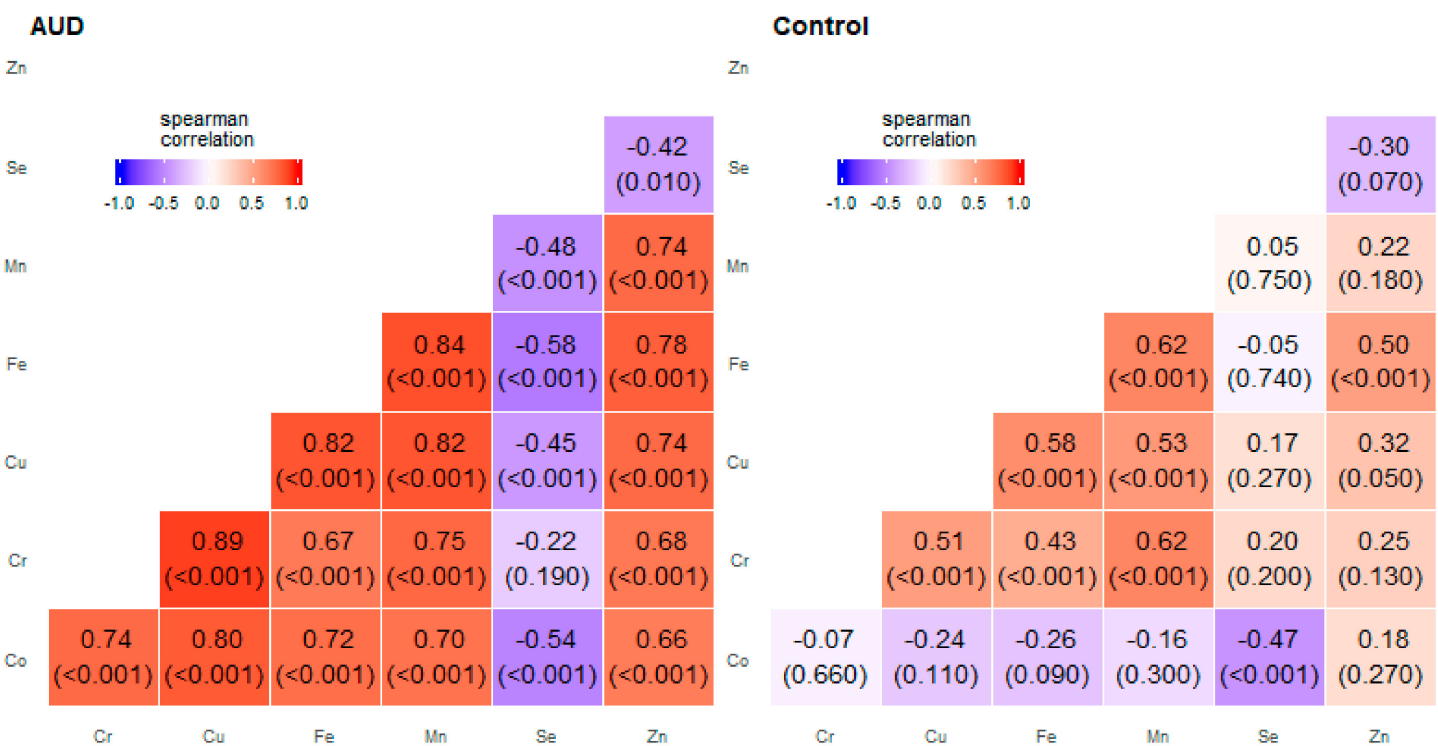

Figure 1. Correlation matrix of average brain trace element concentrations in the alcohol use disorder group and control group. The strongest relationships between average concentrations of trace elements are marked in circles.

Table 1. Intervals for correlations in selected pairs of elements in the two studied groups.

\begin{tabular}{ccccc}
\hline \multirow{2}{*}{ Pair of Trace Elements } & \multicolumn{2}{c}{$\begin{array}{c}\text { Alcohol Use Disorder Group } \\
\text { Lower Bound }\end{array}$} & \multicolumn{2}{c}{ Control Group } \\
Upper Bound & Lower Bound & Upper Bound \\
\hline Co-Cr & 0.03 & 0.74 & -0.30 & 0.41 \\
Co-Cu & 0.21 & 0.62 & -0.44 & 0.22 \\
Co-Fe & 0.19 & 0.72 & -0.59 & 0.62 \\
Co-Mn & 0.12 & 0.69 & -0.35 & 0.09 \\
Cr-Cu & 0.42 & 0.74 & 0.45 & 0.67 \\
Cr-Mn & 0.34 & 0.72 & 0.39 & 0.78 \\
Cu-Fe & 0.67 & 0.86 & 0.46 & 0.83 \\
Cu-Mn & 0.56 & 0.8 & 0.22 & 0.78 \\
Cu-Zn & 0.52 & 0.84 & -0.10 & 0.32 \\
Fe-Mn & 0.45 & 0.90 & 0.39 & 0.88 \\
Fe-Zn & 0.26 & 0.97 & 0.10 & 0.56 \\
$\mathrm{Mn}-\mathrm{Zn}$ & 0.57 & 0.85 & -0.03 & 0.51 \\
\hline
\end{tabular}


In the $\mathrm{Co}-\mathrm{Al}$ pair of elements, there was a slight positive correlation in the frontal cortex region, the caudate nucleus, the thalamus region and the cingular cortex region.

For the $\mathrm{Co}$ and $\mathrm{Cr}$ pair in the group exposed to alcohol, positive correlations were found for the following locations: frontal cortex, dorsal anterior cingular cortex, the head of the caudate nucleus and the frontal part of the thalamus. For this pair of elements in the control group, a moderate positive relationship was found in the frontal cortex region and a weak negative correlation was found in the foot of the hippocampus.

In the $\mathrm{Co}-\mathrm{Fe}$ pair, a positive association was observed in the alcohol use disorder group in all studied regions, except the foot of the hippocampus and the frontal part of the insula region. In contrast, in the control group, for the nucleus accumbens, superior longitudinal fasciculus and frontal part of the insula region, a moderate negative correlation was found. The strongest negative correlation was in the frontal part of the insula.

For the pair of elements $\mathrm{Co}-\mathrm{Mn}$ in the alcohol use disorder group, positive correlations were found in most of the studied structures, with the exception of the inferior longitudinal fasciculus, frontal part of the insula and foot of the hippocampus. A statistically significant negative relationship was observed in the group not exposed to the alcohol factor only for the frontal part of the insula structure.

In the $\mathrm{Cr}-\mathrm{Cu}$ pair, a moderately positive relationship was found in 10 studied areas. In the control group, a similar relationship was observed in a few areas.

Between $\mathrm{Cu}$ and $\mathrm{Fe}$, moderate and strong relationships were found in the examined areas of the brain in both groups included in the study.

In case of $\mathrm{Cu}-\mathrm{Mn}$, as for $\mathrm{Zn}-\mathrm{Mn}$, high correlation coefficients were observed in all studied areas, indicating a strong positive relationship. In the control group, such dependence is also observed, but slightly weaker.

Positive correlations of $\mathrm{Cr}$ and $\mathrm{Mn}$ were observed in both groups.

In the $\mathrm{Cu}-\mathrm{Zn}$ pair, a positive correlation was found in the alcohol use disorder group in all studied regions. In the control group, the relationship was not statistically significant in most of the studied areas.

Between Fe and Mn, positive correlations were observed in all of the analyzed locations in both groups, however they were slightly stronger in the alcohol use disorder group.

AUD

$\mathrm{Zn}$

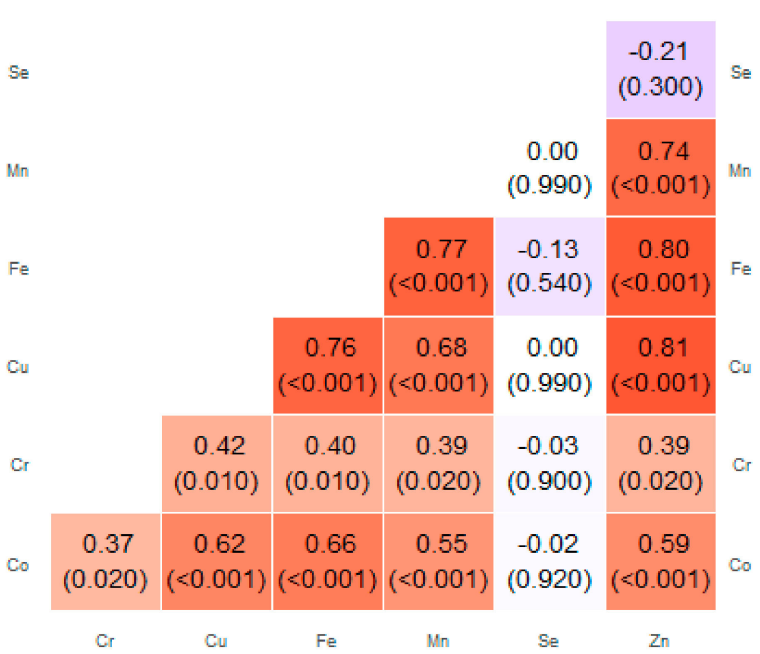

Control

Zn

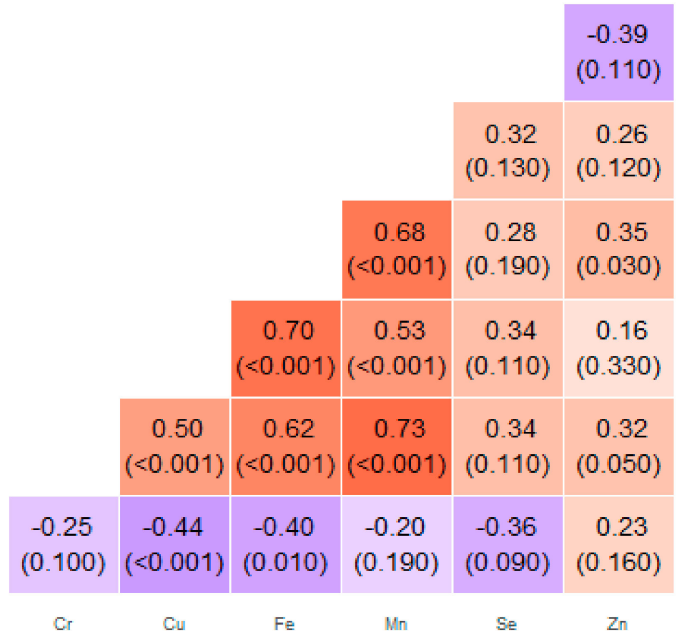

Figure 2. Correlation matrix of Spearman coefficient charts in the anterior cingular cortex region in the alcohol use disorder and control groups. 


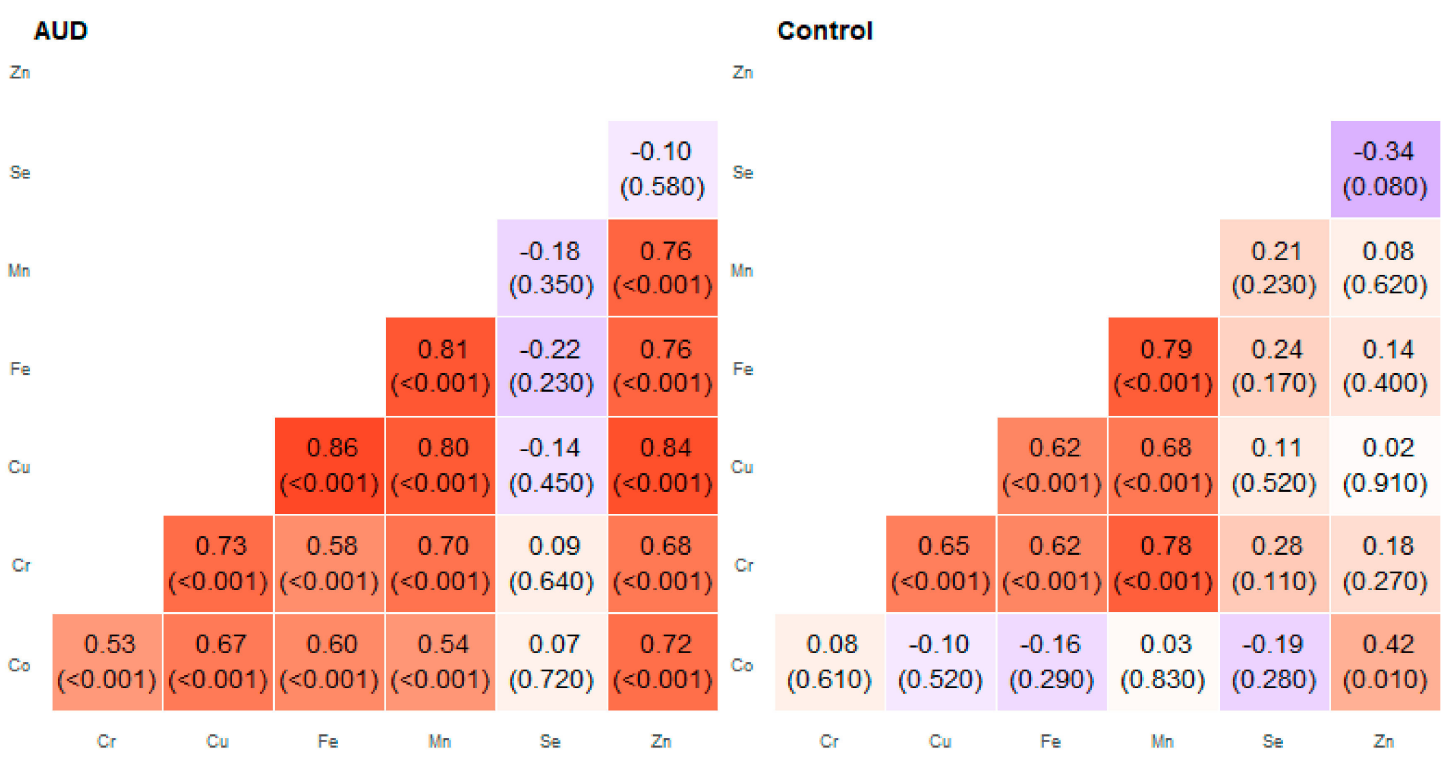

Figure 3. Correlation matrix of Spearman coefficient charts in the head of the caudate nucleus region in the alcohol use disorder and control groups.

In the group with alcohol use disorder for the studied Fe-Zn pair of elements, strong positive monotone relationships were found in all examined brain structures. The relationship was strongest in the frontal part of the insula.

The Mn-Zn pair of elements had high positive correlations in all tested areas of the group exposed to the alcohol factor. In the control group, a moderate positive association was found in the frontal cortex and superior longitudinal fasciculus region.

Correlation matrices comparisons by Schott test were performed (Table 2). Test statistics and $p$-values for particular regions are listed below. All comparisons showed significant differences in correlation matrices between groups.

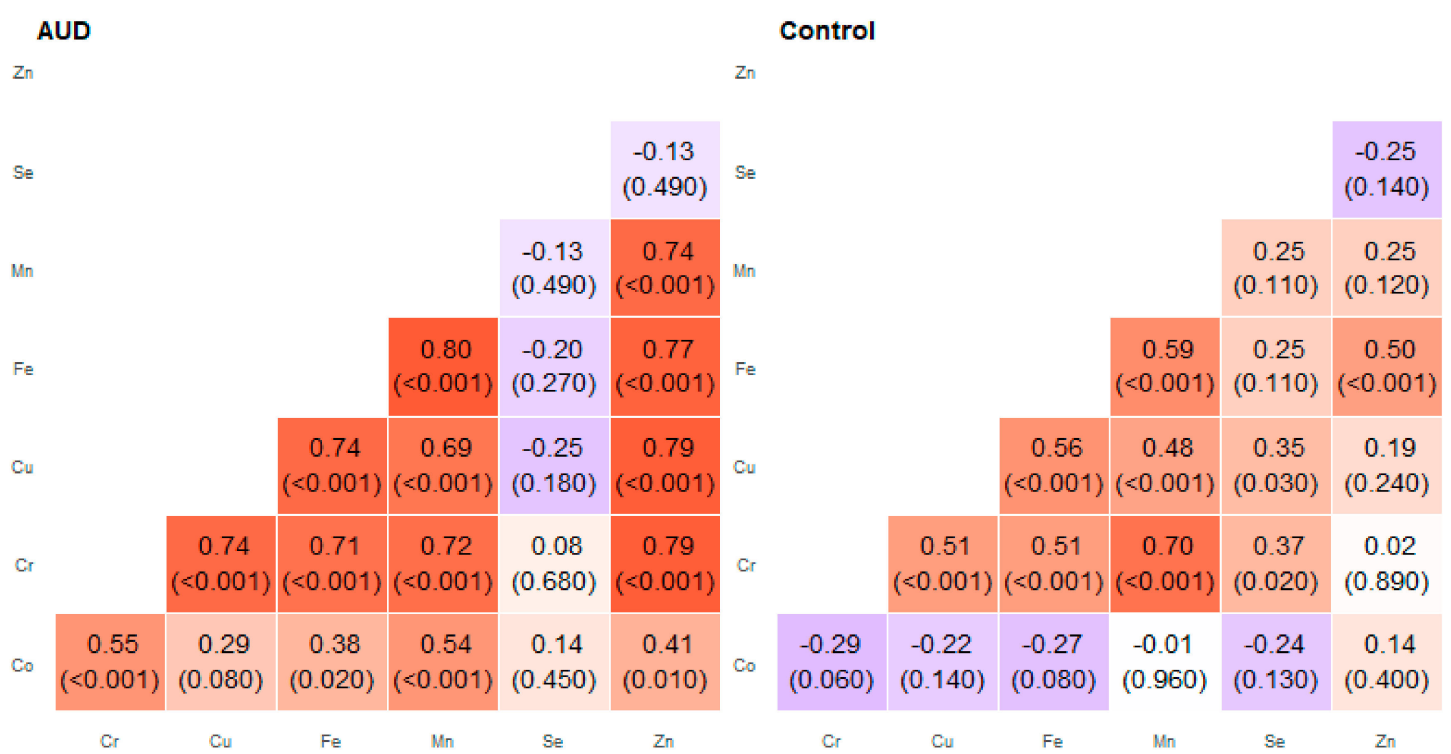

Figure 4. Correlation matrix of Spearman coefficient charts in the frontal part of the thalamus region in the alcohol use disorder and control groups. 


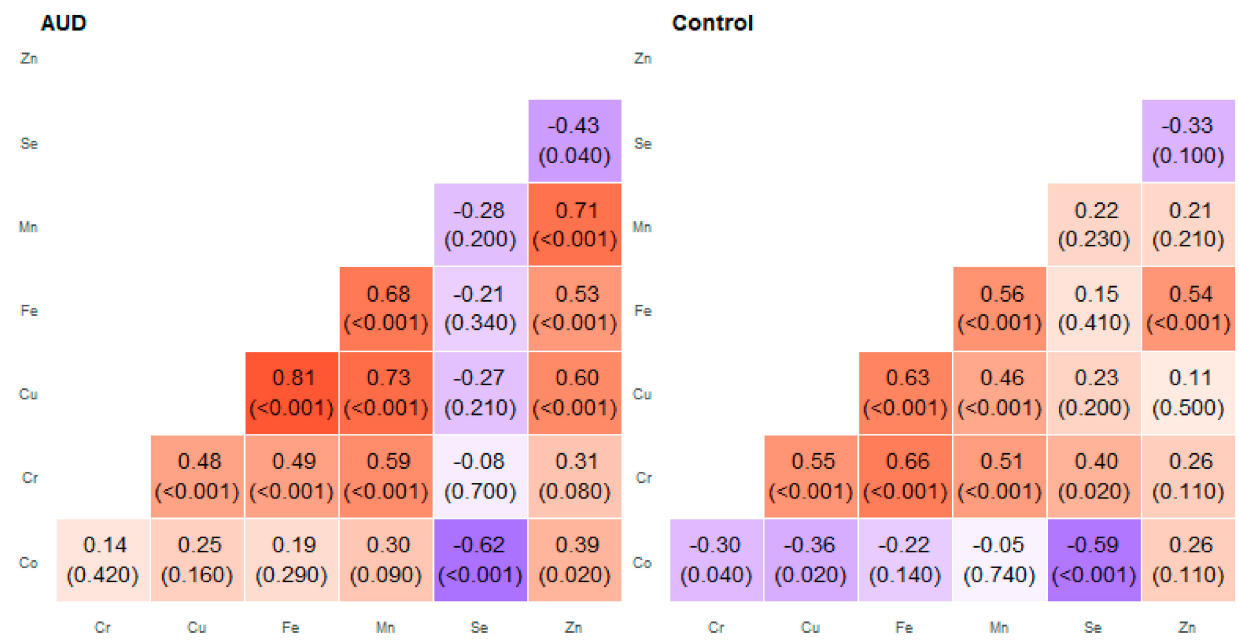

Figure 5. Correlation matrix of Spearman coefficient charts in the foot of the hippocampus region in the alcohol use disorder and control groups.

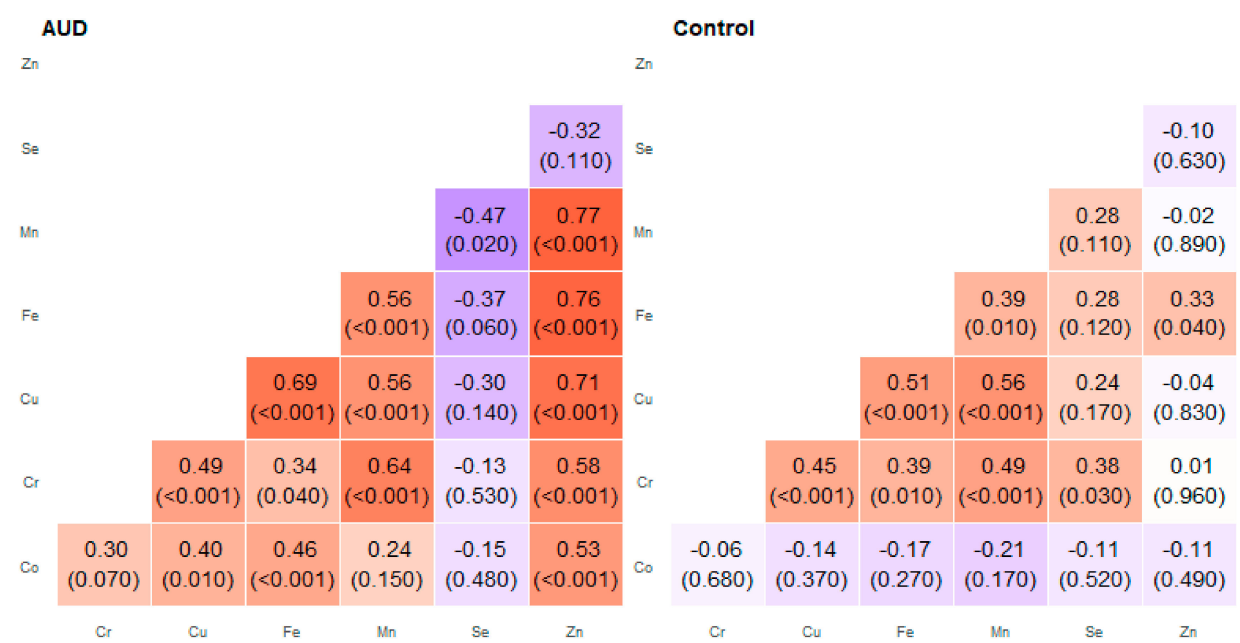

Figure 6. Correlation matrix of Spearman coefficient charts in the inferior longitudinal fasciculus region in the alcohol use disorder and control groups.

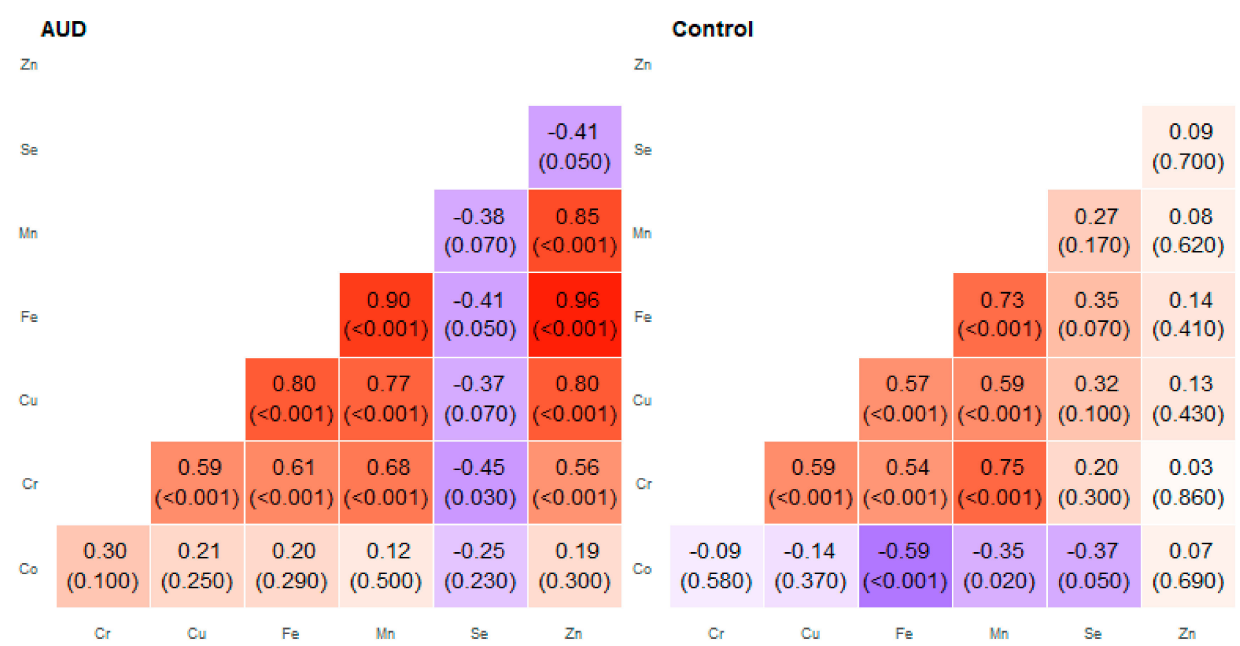

Figure 7. Correlation matrix of Spearman coefficient charts in the frontal part of the insula region in the alcohol use disorder and control groups. 


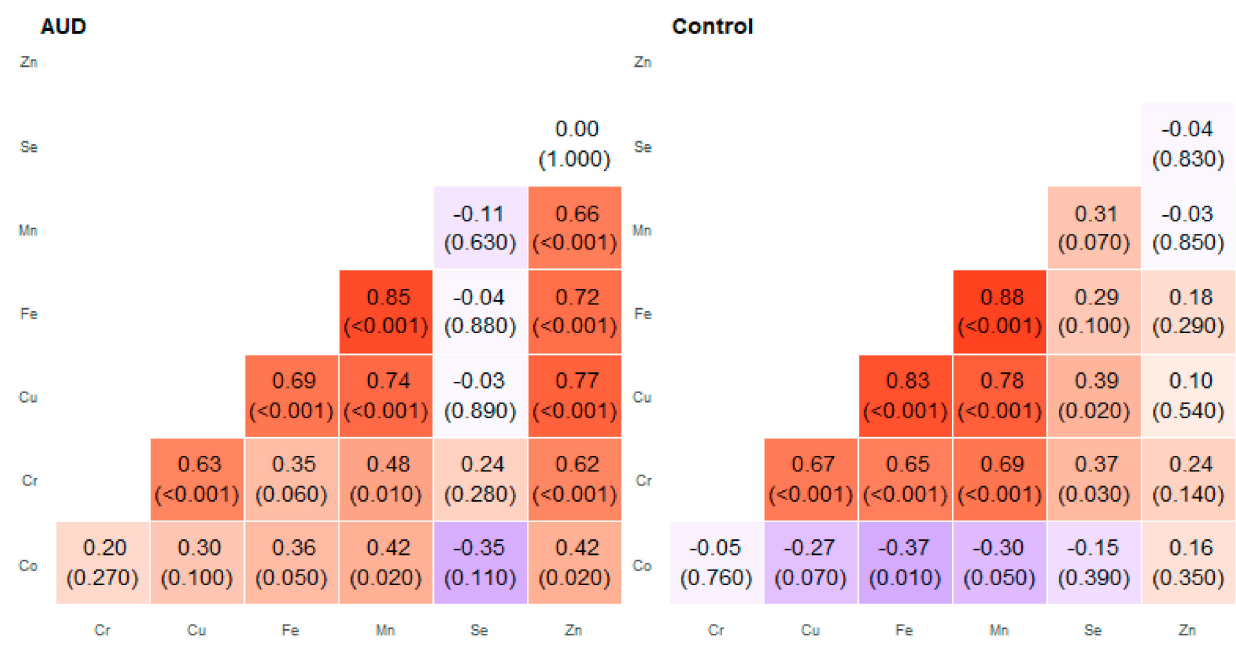

Figure 8. Correlation matrix of Spearman coefficient charts in the nucleus accumbens region in the alcohol use disorder and control groups.

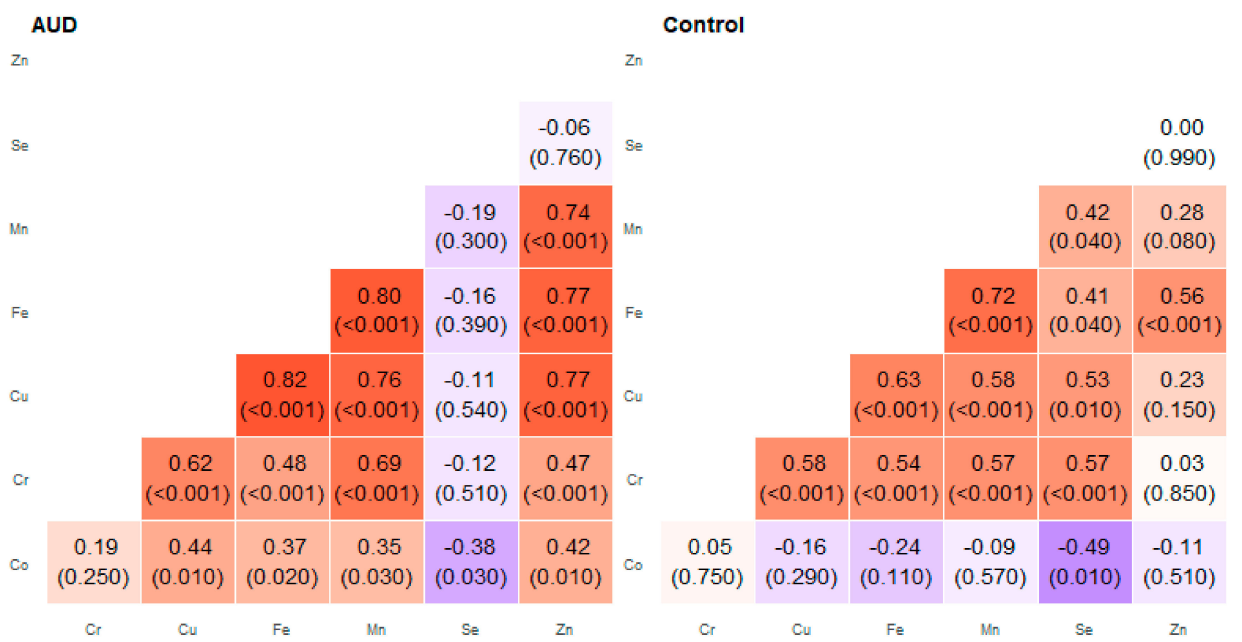

Figure 9. Correlation matrix of Spearman coefficient charts in the post central gyrus region in the alcohol use disorder and control groups.

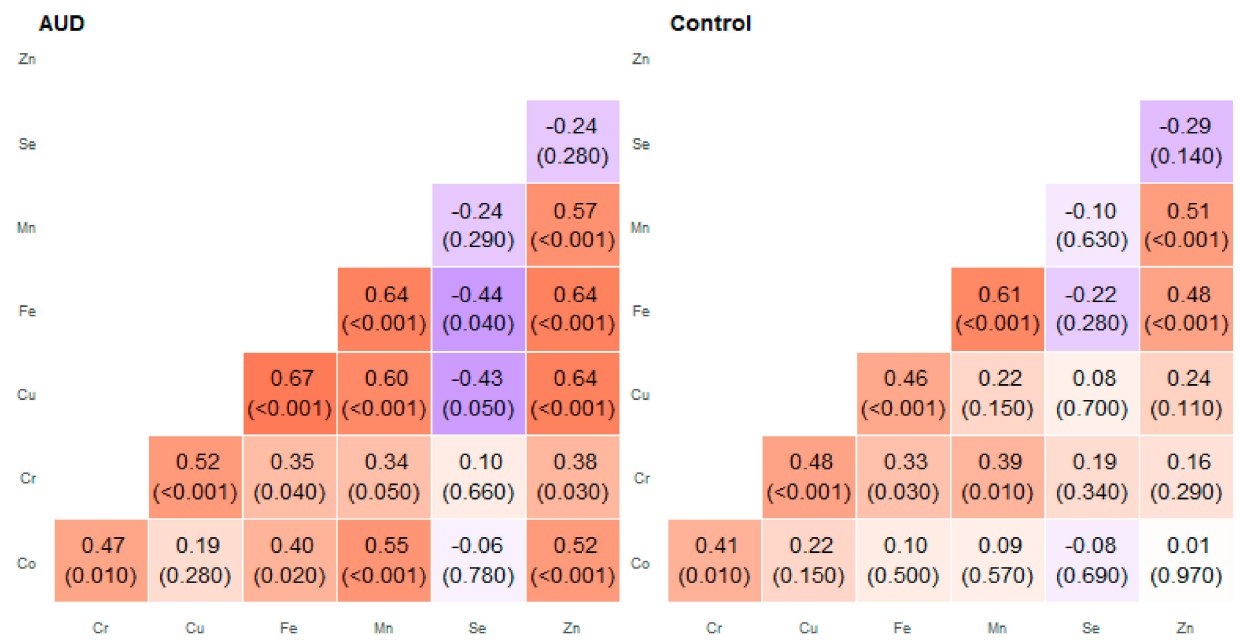

Figure 10. Correlation matrix of Spearman coefficient charts in the frontal cortex region in the alcohol use disorder and control groups. 


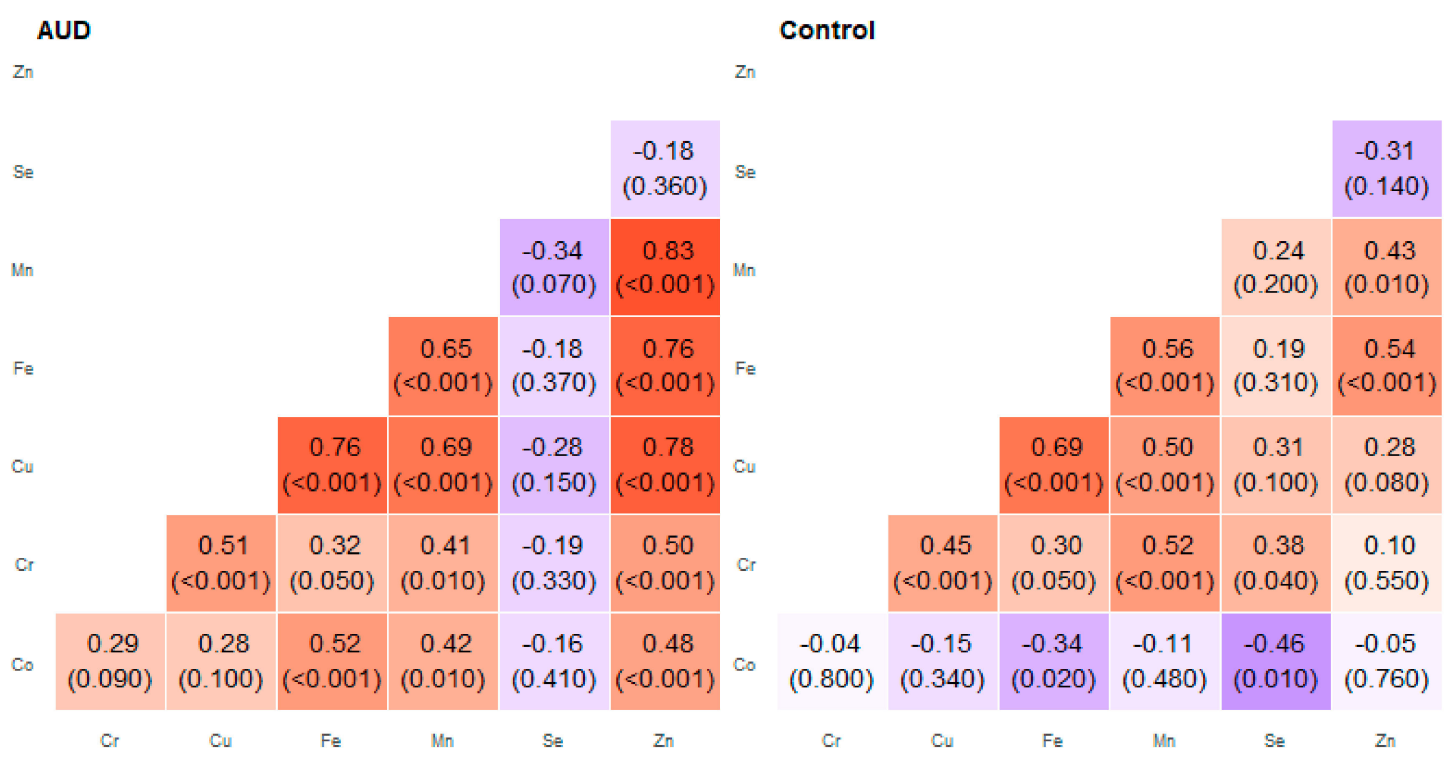

Figure 11. Correlation matrix of Spearman coefficient charts in the superior longitudinal fasciculus region in the alcohol use disorder and control groups.

Table 2. Tests for equality of correlation coefficient matrices by Schott method.

\begin{tabular}{ccc}
\hline Region & Statistic & $p$-value \\
\hline Dorsal anterior cingular cortex & 56.91 & $<0.001$ \\
The head of the caudate nucleus & 26.58 & $<0.001$ \\
Frontal part of the thalamus & 41.46 & $<0.001$ \\
The foot of the hippocampus & 27.39 & $<0.001$ \\
Inferior longitudinal fasciculus & 40.44 & $<0.001$ \\
Frontal part of the insula & 37.78 & $<0.001$ \\
Nucleus accumbens & 38.32 & $<0.001$ \\
Post central gyrus & 38.04 & $<0.001$ \\
Frontal cortex & 42.20 & $<0.001$ \\
Superior longitudinal fasciculus & 29.71 & $<0.001$ \\
Total (average value) & 65.09 & $<0.001$ \\
\hline
\end{tabular}

\section{Discussion}

In this paper, several pairs of trace elements were presented which significantly statistically correlated with each other. Given that there are plenty of complex transport mechanisms for each element, it is problematic to discuss the kinetic interactions between these trace elements. However, further research is necessary regarding distribution and mutual correlation of trace elements [12,14-17].

There are approximately $7 \%$ of individuals throughout the world over 18 years of age who are considered to be habitual consumers of alcohol. Undoubtedly, alcoholic beverages are the source of different trace elements. Data presented by Darret et al. show that beer is a source of $\mathrm{Cr}$ and Se and wine contains large amounts of $\mathrm{Al}, \mathrm{Cr}, \mathrm{Ni}, \mathrm{Zn}$ and $\mathrm{Mg}$ [18].

In the study assessing $\mathrm{Cr}$ and Se relationships in chicken brains, it was found that the group exposed to selenium and chromium had a lower concentration of chromium in tissues than the group exposed only to chromium. A clear negative correlation was observed in the pair of elements $\mathrm{Cr}$ and Se [19]. This does not correspond with the results obtained in this study. In the alcohol use disorder group, no significant relationship between these elements was found. On the other hand, in the control group, a moderate positive correlation was observed in most of the studied areas.

Research conducted by Rahil-Khazen et al. reports a positive correlation of many element pairs in the soft tissues of healthy patients $(n=30)$ such as the brain, liver, cortex and spleen. Most dependencies 
were found in the renal cortex and medulla (e.g., Fe-Co, Cu-Mn, Zn-Mn, Cu-Se and Zn-Cu). There was a strong positive relationship in the Fe-Co pair of trace elements in the brain [20]. On the contrary, in this study, a moderate negative relationship between Fe and Co in tissues from the nucleus accumbens, frontal part of the insula, anterior cingular cortex, and superior longitudinal fasciculus regions was found in the control group. In the alcohol use disorder group, a moderate positive correlation was found for most of the studied areas.

The literature describes a significant positive correlation between $\mathrm{Cu}, \mathrm{Fe}, \mathrm{Zn}$ and $\mathrm{Mn}$ in different human organs, which was consistent with the results obtained in this study [21]. Another study performed by Rahil-Khazen et al. reports that $\mathrm{Zn}-\mathrm{Fe}$ had a negative correlation in soft tissues such as the brain, liver, kidney cortex and spleen, which is opposite to the results found in this study in patients with alcohol use disorder [22]. Moreover, several studies have shown that ethanol increases the permeability of the blood-brain barrier [23,24] as well as the blood-cerebrospinal fluid barrier [25]. Kornhuber et al. suggest that the permeability of these barriers is increased not only due to the dosage of consumed alcohol, but also by chronic intake.

The majority of correlations between elements in this study are positive and have bigger strengths among the group with alcohol use disorder compared to the control group, which may suggest a dysfunction within the blood-brain barrier in those individuals. Moreover, it is well known that disturbed homeostasis of elements such as Al [26], Fe [27], Zn and Cu [28] as well as alcohol itself induces oxidative stress processes, which increase the permeability of the blood-brain barrier. Moreover, it causes malfunction of endothelial cells [24], which are partially responsible for transportation within the blood-brain barrier [29]. Improper function of the blood-brain barrier may promote the accumulation of trace elements within brain tissue, which are known to cause neurodegeneration [30,31].

\section{Materials and Methods}

\subsection{Population}

Brain tissue samples were taken from individuals who underwent autopsy in the Department of Forensic Medicine, University of Lublin, Lublin, Poland. The authors harvested tissue samples from 31 people ( 8 female and 23 male) suffering from alcoholic use disorder. The inclusion criteria included no history of mental disorders, alcohol abuse reported in medical history as well as alcohol level over 2 per mil confirmed in blood at the time of the section. Moreover, thirty-one control subjects (Table 3) underwent tissue harvesting with inclusion criteria of macroscopically unaltered brain tissue, lack of documented neurodegenerative disease and alcoholic disorder history and blood alcohol level 0 per mil, confirmed at the time of the section. The study was approved by the Local Ethical Committee (Medical University of Lublin, Poland, approval no. KE-0254/2018) and the tissue collection was approved by the prosecutor's office. The research has been carried out in accordance with The Code of Ethics of the World Medical Association, Declaration of Helsinki for experiments involving humans.

Table 3. Demographic characteristics of analyzed subjects. $\mathrm{AUD}=$ alcohol use disorder, $\mathrm{SD}=$ standard deviation.

\begin{tabular}{cccc}
\hline Parameter & Control Group & AUD Group & $p$ \\
\hline Age $($ mean $\pm \mathrm{SD})$ & $50.3 \pm 19.1$ & $47.9 \pm 13.3$ & 0.41 \\
Sex $(\mathrm{n}, \%)$ & Women: $8(26 \%)$ & Women: $10(32 \%)$ & 0.58 \\
Weight $($ mean $\pm \mathrm{SD})$ & Men: $23(74 \%)$ & Men: $21(68 \%)$ & 0.64 \\
BMI $\left(\mathrm{kg} / \mathrm{m}^{2}\right.$, mean $\left.\pm \mathrm{SD}\right)$ & $28.0 \pm 20.9$ & $81.4 \pm 25.4$ & 0.65 \\
\hline
\end{tabular}

\subsection{Procedure of Tissue Collection}

Qualified pathologists collected the samples in accordance with the analytical protocol. Suprapure nitric acid solution $(5 \%(v / v))$ was used to decontaminate all of the materials that were in contact 
with the tissue samples. Moreover, ultrapure water (Milli-Q, Millipore, Raleigh, NC, USA; resistivity: $18.2 \mathrm{M} \Omega \cdot \mathrm{cm}$ ) was used to thoroughly wash the tools.

The brain was removed from the cranium and washed with ultrapure water. Plastic tweezers were used to remove the meninges and the brain was rinsed with ultrapure water in order to reduce the probability of sample contamination with cerebrospinal fluid or blood. Disinfected plastic knives were used to collect tissue samples (approximately $0.5 \mathrm{~g}$ ) from ten anatomical brain structures: frontal cortex (Broadmann area no. 11, PFC), dorsal anterior cingular cortex (Broadmann area no. 32, ACC), post central gyrus (Broadmann area no. 1, PCG), the foot of the hippocampus (HPC), frontal part of the thalamus (FTH), nucleus accumbens (NAC), frontal part of the insula (INS), the head of the caudate nucleus (CA), superior longitudinal fasciculus (SLF), and inferior longitudinal fasciculus (ILF). The selection of brain regions was based on their functional properties (memory, aggression, addiction, higher cognitive functions, emotion). Tissue samples were thoroughly rinsed with deionized water, drained on sterile blotting paper and weighed afterwards. All samples were put into sterile polypropylene containers (Bionovo, Legnica, Poland) and initially decayed with the use of $2 \mathrm{~mL}$ of $65 \%$ suprapure nitric acid. There was limited mass loss of the samples, which were digested directly after sampling without preliminary drying. In the last stage of the experiment, each sample was quantitatively transferred to closed Teflon containers and digested at $180^{\circ} \mathrm{C}$ utilizing the microwave digestion system Mars 6 (CEM Corporation, Matthews, NC, USA). After digestion, samples were diluted with water to meet a total volume of $10.0 \mathrm{~mL}$ using scaled test-tubes.

\subsection{Analytical Procedure}

The inductively coupled plasma optical emission spectrometer Agilent 5110 ICP-OES (Agilent, Santa Clara, CA, USA) was employed for trace element determination. The synchronous vertical dual view (SVDV) of the plasma was accomplished by using dichronic spectral combiner (DSC) technology. This allows simultaneous axial and radial view analysis. In doing so, radio frequency (RF) power was $1.2 \mathrm{~kW}$, nebulizer gas flow was $0.7 \mathrm{~L} \mathrm{~min}^{-1}$, auxiliary gas flow was $1.0 \mathrm{~L} \mathrm{~min}^{-1}$, plasma gas flow was $12.0 \mathrm{~L} \mathrm{~min}^{-1}$, charge coupled device $(\mathrm{CCD})$ temperature was $-40^{\circ} \mathrm{C}$, viewing height for radial plasma observation was $8 \mathrm{~mm}$, and accusation time was $5 \mathrm{~s}$. The analysis was repeated three times. The method has been validated using a wide organic matrix in several certified materials. The obtained results are given in the Supplementary Materials. Validation data for the determination of elements by this method are presented in Table 4. Due to the fact that certified reference materials (CRMs) of brain tissue are not available, the analytical method was additionally assessed by the standard additions method. ICP commercial analytical standards (Romil, Cambridge, UK) were used both for calibration and standard additions. Detection limits (DL) were determined through 3-sigma criteria and were on the level of $0.01(\mathrm{mg} / \mathrm{kg})$ wet weight $(w / w)$ for all elements determined. The uncertainty for the complete analytical process (including sample preparation) was at the level of $20 \%$. Traceability was assessed by comparison with reference materials. A recovery of $80-120 \%$ was considered acceptable for all the elements determined.

Table 4. Validation data for elements determination by inductively coupled plasma optical emission spectroscopy (ICP-OES).

\begin{tabular}{ccccc}
\hline & $\begin{array}{c}\text { Wavelength } \\
\text { nm }\end{array}$ & $\begin{array}{c}\text { DL } \\
\text { mg L }^{-1}\end{array}$ & $\begin{array}{c}\text { Range } \\
\text { mg L }^{-1}\end{array}$ & $\begin{array}{c}\text { Uncertainty } \\
\text { \% }\end{array}$ \\
\hline $\mathrm{Co}$ & 238,892 & 0.00029 & DL-20 & 1.6 \\
$\mathrm{Cr}$ & 267,716 & 0.00033 & DL-20 & 4.0 \\
$\mathrm{Cu}$ & 327,395 & 0.00027 & DL-20 & 9.6 \\
$\mathrm{Fe}$ & 238,204 & 0.00084 & DL-100 & 1.6 \\
$\mathrm{Mn}$ & 257,610 & 0.00021 & DL-20 & 1.8 \\
$\mathrm{Se}$ & 196,026 & 0.0011 & DL-10 & 16.4 \\
$\mathrm{Zn}$ & 213,857 & 0.00022 & DL-20 & 3.5 \\
\hline
\end{tabular}




\subsection{Statistical Analysis}

The correlations between concentrations of individual elements in the brain were analyzed in terms of their magnitude and direction. Correlation and covariance analyses were performed. Since elemental concentrations in different areas may have an abnormal distribution, Spearman's coefficient was used to test the correlation. Spearman's correlation coefficients were calculated for each brain region divided into control and alcohol use disorder groups. $p$-values were also included in figures (numbers in brackets). Intervals for correlations in pairs of elements in two studied groups are presented in Table 3. The differences between matrices of correlations were tested with the Schott test, which is a generalization of the Box M test for homogeneity of covariance matrices. This generalization is robust for non-normality. All variables were scaled before testing, so covariance matrices turned to correlation matrices [14]. The significance level ( $p$-value) adopted in this work is 0.05. All statistical calculations and visualizations were done in R environment (R Core Team $2019 \mathrm{R}$ Foundation for Statistical Computing, Vienna, Austria) with extra packages such as ggplot2, dplyr, purrr, and ggcorrplot.

\section{Conclusions}

The results of this study showed a great number of correlations between different trace elements in the human brain. Statistically significant alterations were found between individuals with alcohol use disorder and the control group. More correlations were observed in the AUD group and they were stronger than those found in the controls. The knowledge of kinetics and metabolism of trace elements, as well as the impact of alcohol to this process, is essential for understanding the pathological processes and functioning of human brain tissue.

Supplementary Materials: The following are available online at http://www.mdpi.com/1420-3049/25/2/359/s1, Table S1: Descriptive statistics. Statistics were calculated for each element by tested areas and groups (for data before logarithmic transformation). Table S2: Results of certified reference materials analysis

Author Contributions: Conceptualization, C.G., E.B; methodology, E.B., P.N., J.P..; software, J.P.; validation, J.P., P.N.; formal analysis, E.B.; investigation, C.G., J.L., A.B.; resources, P.N.; data curation, D.M.; writing-Original draft preparation, C.G., M.S., A.B., J.L.; writing-Review and editing, M.S., P.N., D.M.; visualization, D.M.; supervision, C.G.; project administration, C.G.; funding acquisition, E.B., P.N. All authors have read and agreed to the published version of the manuscript. Please turn to the CRediT taxonomy for the term explanation. Authorship must be limited to those who have contributed substantially to the work reported.

Funding: This research received no external funding.

Conflicts of Interest: The authors declare no conflict of interest.

\section{References}

1. Griffith, G.C.; Butt, E.M.; Walker, J. The inorganic element content of certain human tissues. Ann. Intern. Med. 1954, 41, 501-509. [CrossRef] [PubMed]

2. Perry, H.M., Jr.; Tipton, I.H.; Schroeder, H.A.; Cook, M.J. Variability in the metal content of human organs. J. Lab. Clin Med. 1962, 60, 245-253.

3. Tipton, I.H.; Schroeder, H.A.; Perry Jr, H.M.; Cook, M.J. Trace Elements in Human Tissue: III. Subjects from Africa, the near and Far East and Europe. Health Phys. 1965, 11, 403-451. [CrossRef] [PubMed]

4. Grochowski, C.; Blicharska, E.; Baj, J.; Mierzwińska, A.; Brzozowska, K.; Forma, A.; Maciejewski, R. Serum iron, Magnesium, Copper, and Manganese Levels in Alcoholism: A Systematic Review. Molcules 2019, 24, 1361. [CrossRef]

5. Verma, P.K.; Sharma, A.; Shankar, H.; Sharma, A.; Rao, D.N. Role of Trace Elements, Oxidative Stress and Immune System: A Triad in Premature Ovarian Failure. Biol. Trace Elem. Res. 2017, 184, 325-333. [CrossRef]

6. Cicero, C.E.; Mostile, G.; Vasta, R.; Rapisarda, V.; Signorelli, S.S.; Ferrante, M.; Zappia, M.; Nicoletti, A. Metals and neurodegenerative diseases. A systematic review. Environ. Res. 2017, 159, 82-94. [CrossRef]

7. Grochowski, C.; Radzikowska, E.; Maciejewski, R. Neural stem cell therapy-Brief review. Clin. Neurol. Neurosurg. 2018, 173, 8-14. [CrossRef] 
8. Duce, J.A.; Bush, A.I. Biological metals and Alzheimer's disease: Implications for therapeutics and diagnostics. Prog. Neurobiol. 2010, 92, 1-18. [CrossRef]

9. Grochowski, C.; Litak, J.; Kulesza, B.; Szmygin, P.; Ziemianek, D.; Kamieniak, P.; Szczepanek, D.; Rola, R.; Trojanowski, T. Size and location correlations with higher rupture risk of intracranial aneurysms. J. Clin. Neurosci. 2018, 48, 181-184. [CrossRef]

10. Grochowski, C.; Staśkiewicz, G. Ultra high field TOF-MRA: A method to visualize small cerebral vessels. 7 T TOF-MRA sequence parameters on different MRI scanners-Literature review. Neurol. Neurochir. Pol. 2017, 51, 411-418. [CrossRef]

11. Rehm, J.; Samokhvalov, A.V.; Neuman, M.G.; Room, R.; Parry, C.; Lönnroth, K.; Patra, J.; Poznyak, V.; Popova, S. The association between alcohol use, alcohol use disorders and tuberculosis (TB). A systematic review. BMC Public Health. 2009, 9, 450. [CrossRef] [PubMed]

12. Rehm, J. The risks associated with alcohol use and alcoholism. Alcohol Res Health. 2011, 34, 135-143.

13. Dinsmore, W.W.; McMaster, D.; Callender, M.E.; Buchanan, K.D.; Love, A.H.G. Trace elements and alcohol. Sci. Total Environ. 1985, 42, 109-119. [CrossRef]

14. Schott, J. Some Tests for the Equality of Covariance Matrices. J. Stat. Plan. Inference 2001, 94, 25-36. [CrossRef]

15. O'Dell, B.L. Mineral interactions relevant to nutrient requirement. J. Nutr. 1989, 119, 1832-1838. [CrossRef]

16. Elsenhans, B.; Schumann, K.; Forth, W. Toxic metals: Interactions with essential metals. In: Rowland IR, ed. Nutr. Toxic. Cancer. 1991, 8, 223-258.

17. Telisman, S. Interactions of essential and/or toxic metals and metalloid regarding interindividual differences in susceptibility to various toxicants and chronic diseases in man. Arh. Hig. Rada. Toksikol. 1995, 46, 459-476.

18. Darret, G.; Couzy, F.; Antoine, J.M.; Magliola, C.; Mareschi, J.P. Estimation of Minerals and Trace Elements Provided by Beverages for the Adult in France. Ann. Nutr. Metab. 1986, 30, 335-344. [CrossRef]

19. Zhu, Y.; Chen, P.; Wan, H.; Wang, Y.; Hao, P.; Liu, Y.; Liu, J. Selenium-Chromium (VI) Interaction Regulates the Contents and Correlations of Trace Elements in Chicken Brain and Serum. Biol. Trace Elem. Res. 2018, 181, 154-163. [CrossRef]

20. Rahil-Khazen, R.; Bolann, B.J.; Ulvik, R.J. Correlations of trace element levels within and between different normal autopsy tissues analyzed by inductively coupled plasma atomic emission spectrometry (ICP-AES). BioMetals 2002, 15, 87-98. [CrossRef]

21. Tanaka, M.; Matsugi, E.; Miyasaki, K. PIXE measurement applied to trace elemental analysis of human tissues. Nucl. Instrum. Meth. B. 1987, 22, 152-155. [CrossRef]

22. Rahil-Khazen, R.; Bolann, B.J.; Myking, A.; Ulvik, R.J. Multi-element analysis of trace element levels in human autopsy tissues by using inductively coupled atomic emission spectrometry technique (ICP-AES). J. Trace Elem. Med. Biol. 1987, 16, 15-25. [CrossRef]

23. Gulati, A.; Chandishwar, N.; Shanker, K.; Srimal, R.C.; Dhawan, K.N.; Bhargava, K.P. Effect of alcohols on the permeability of blood-brain barrier. Pharm. Res. Commun. 1985, 17, 85-93. [CrossRef]

24. Haorah, J. Alcohol-induced oxidative stress in brain endothelial cells causes blood-brain barrier dysfunction. J. Leukoc. Biol. 2005, 78, 1223-1232. [CrossRef]

25. Kornhuber, J.; Kaiserauer, C.H.; Kornhuber, A.W.; Kornhuber, M.E. Alcohol Consumption and Blood-Cerebrospinal Fluid Barrier Dysfunction in Man. Neuroscience 1987, 79, 218-222. [CrossRef]

26. Kumar, V.; Gill, K.D. Oxidative Stress and Mitochondrial Dysfunction in Aluminium Neurotoxicity and Its Amelioration: A Review. NeuroToxicology 2014, 41, 154-166. [CrossRef]

27. Puntarulo, S. Iron, Oxidative Stress and Human Health. Mol. Aspects Med. 2005, 26, 299-312. [CrossRef]

28. Deibel, M.; Ehmann, W.; Markesbery, W. Copper, Iron, and Zinc Imbalances in Severely Degenerated Brain Regions in Alzheimer's Disease: Possible Relation to Oxidative Stress. J. Neurol. Sci. 1996, 143, 137-142. [CrossRef]

29. Lochhead, J.J.; McCaffrey, G.; Quigley, C.E.; Finch, J.; DeMarco, K.M.; Nametz, N.; Davis, T.P. Oxidative Stress Increases Blood-Brain Barrier Permeability and Induces Alterations in Occludin during Hypoxia-Reoxygenation. J. Cereb. Blood Flow Metab. 2010, 30, 1625-1636. [CrossRef] 
30. Bolognin, S.; Messori, L.; Zatta, P. Metal Ion Physiopathology in Neurodegenerative Disorders. Neuro. Mol. Med. 2009, 11, 223-238. [CrossRef]

31. Bowman, A.B.; Kwakye, G.F.; Herrero Hernández, E.; Aschner, M. Role of Manganese in Neurodegenerative Diseases. J. Trace Elem. Med. Biol. 2011, 25, 191-203. [CrossRef] [PubMed]

Sample Availability: Samples of the compounds are available from the authors.

(C) 2020 by the authors. Licensee MDPI, Basel, Switzerland. This article is an open access article distributed under the terms and conditions of the Creative Commons Attribution (CC BY) license (http://creativecommons.org/licenses/by/4.0/). 